\title{
Li-Fi technology: A Era of New Data Transmission
}

\author{
D.O.I - 10.51201/12519 \\ https://doi.org/10.51201/12519 \\ P. S. Patil*1, R.M.Ingle ${ }^{2}$, Rohit Sarve ${ }^{3}$, Sajal Jaipurkar ${ }^{3}$ \\ ${ }^{1}$ Asst. Prof., YCCE, Nagpur, \\ ${ }^{2}$ Asst. Prof., JIT, Nagpur, \\ ${ }^{3}$ Student, YCCE, Nagpur
}

\begin{abstract}
The main focus of this paper is to clarify the concept and working of Li-Fi technology. In present era, wireless communication plays an important role in day to day life. Wifi is the most used wireless technology which transmits data through radio frequencies. However, during multiple accesses WiFi is facing many challenges related to speed, security and efficiency. Also, WiFI emits radio waves which are harmful in hospitals for patients and cannot be used in underground communication and airplanes. These limitations of WiFi are overcome by Li-Fi technology. The term Li-Fi stands for Light Fidelity which uses visible light communication (VLC) to transfer data at high speed. In this paper, a detailed study on Li-Fi technology, its working and future scope is discussed.
\end{abstract}

Keywords: Lifi, Wifi, VLC

\section{INTRODUCTION}

Professor Harald Haas, a German physicist coined the term Li-Fi(Light Fidelity) during his Global TED Talk in 2011. He demonstrated this technology using a working model in which a video of blooming flower was transmitted using LED lamp and the video transmitted through visible light was projected on the screen. He then blocked the light from LED lamp to show that the video is transmitted through light only. In wireless communication Wi-Fi uses WiFi modems to transmit data in the form of radio waves. Whereas, Li-Fi uses LED light to transmit data using visible light communication (VLC). The speed of light is very high. Hence the speed of data transmission is more in Li-Fi as compared to Wi-fi which transmits data through radio waves. Wi-Fi uses frequencies of order $4 \times 10^{10}$ whereas Li-Fi uses frequencies in the range of $4 \times 10^{14}-8 \times 10^{14}$. The difference between frequencies of $\mathrm{WiFi}$ and $\mathrm{Li}-\mathrm{Fi}$ is $10,000 \mathrm{~Hz}$ which shows greater bandwidth of LiFi as shown in Fig1.

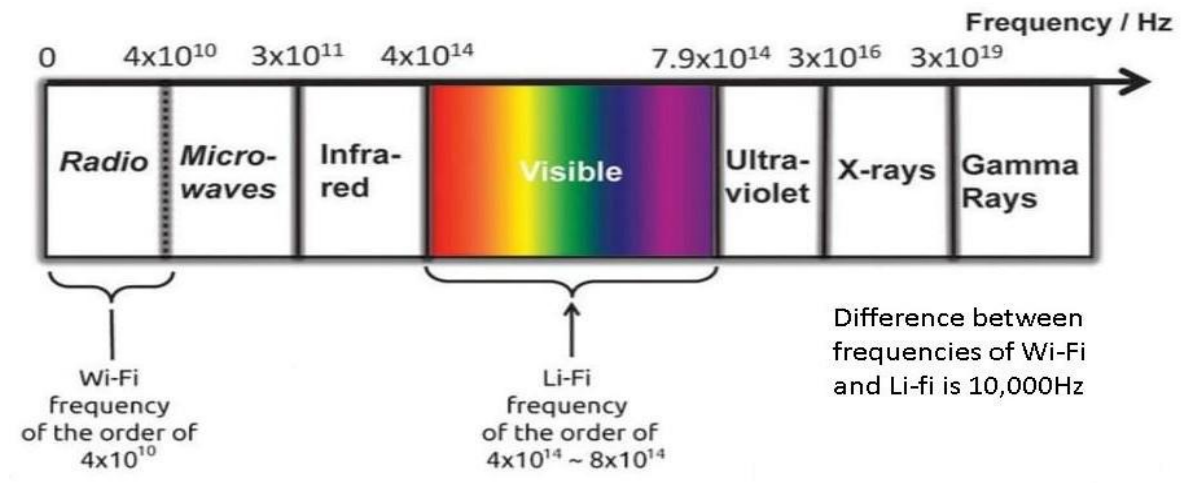

Fig-1: Li-Fi and Wi-Fi Frequency Spectrum usage 
Table 1. Comparison Between Wi-Fi and Li-FI

\begin{tabular}{|l|l|l|}
\hline \multicolumn{1}{|c|}{ Parameters } & \multicolumn{1}{c|}{ Wi-Fi } & \multicolumn{1}{c|}{ Li-Fi } \\
\hline Speed & $100-150 \mathrm{MBPS}$ & Upto 1 GBPS \\
\hline Spectrum & Narrow spectrum & 10000 times broader that of Wi-Fi \\
\hline Data Density & Low & Very High \\
\hline Security & Less Secure & Highly Secure \\
\hline Bandwidth & Low & High due to broad spectrum \\
\hline Environment Impact & High & Low \\
\hline Latency & In Milliseconds $\left(10^{-3}\right)$ & In Microseconds $\left(10^{-6}\right)$ \\
\hline Power Consumption & More & Less \\
\hline
\end{tabular}

\section{Working principle of Li-Fi Technology:-}

The li-fi technology uses VLC system in which data is transmitted in the form of visible light. Due to the high speed and intensity of light, transmission of data at high speed is possible. In Li-Fi, LED lights acts as a transmitter and photo detector (sensor) acts as a receiver which is fitted into devices. When alternating current pass through LED, it starts flickering. When minimum current or no current flows through LED, the brightness of LED will be minimum. This will be treated as OFF and digital ' 0 ' is transmitted at receiver side. Similarly, when maximum amount of current flows through LED, the brightness of LED is maximum and LED is treated as ON so digital ' 1 ' is transmitted at receiver side. In this way by flickering the data at a very high rate we can transmit the data in digital form i.e. in the form of 1's and 0's to the receiver. This flickering of LED is of the order million times per second so it appear as constant light to human eye. At receiver end, a photo detector (photo sensor) receives the signals and converts it back to original data.

\section{LED as a Light Source}

In Li-Fi, LED is used as a light source due to its ability to flicker ON and OFF at a very high rate (ie million times per second). LEDs have many benefits over incandescent lamps and fluorescent bulbs as it consume less energy, environment friendly, longer life and higher efficiency. LEDs are designed in such a way to withstand shocks and vibrations and have a long life more than 1,00,000 hours. Replacing a single LED bulb with an array of micro LEDs can increase the rate of data transfer as micro LEDs flicker at even high rate.

\section{Features of Li-Fi Technology}

\section{Capacity}

In Li-Fi, data is transferred using visible light which have greater bandwidth, unlicensed and free to use. The frequency spectrum of visible light is 1000 times greater than that of radio waves used in Wi-Fi.

\section{Efficiency}

Li-Fi operates on visible light communication. So, LED that are already installed in workplaces, home, offices can be used for data transfer. LED lights consumes less electrical energy and are highly efficient. 
$\underline{\text { Safety }}$

Li-Fi technology can be used where radio waves are prohibited. There is no harmful radiation in $\mathrm{Li}-\mathrm{Fi}$, so it is safe and non-hazardous.

\section{$\underline{\text { Security }}$}

In Li-Fi, light cannot penetrate through walls and opaque objects so data theft and its hacking is almost negligible.

\section{Applications of Li-Fi technology}

$\mathrm{Li}-\mathrm{Fi}$ technology can be used in wide variety of fields. Its various applications are discussed below

\section{1) Power plant and Hazardous mines}

Power plants, petrochemical plants, dangerous mines require wireless communication for monitoring of grids, demand, temperature, etc. However, WiFi cannot be used in such places due to its electromagnetic interference. So, Li-Fi can be used in such applications which uses visible light communication (VLC) and offers a safe alternative.

\section{2) Medical and Healthcare}

Li-Fi can be used in medical and healthcare where Wi-Fi is prohibited such as operation theatre. Radio waves from Wi-Fi can block signals from monitoring devices and medical equipment and it may be hazardous to patients. There is no electromagnetic interference in Li-Fi due to its broader bandwidth so it can be used in modern medical instruments such as MRI scanners.

\section{3) Airlines and Aviation industry}

Wi-Fi is often restricted in airplanes as the radio waves interferes with the signals from air traffic controllers (ATC). So, Li-Fi can be used for data transmission through LED lights which are already available in airplanes.

\section{4) Vehicle to vehicle communication}

Li-Fi can be used for communication between vehicles to prevent accidents. The light from headlights and tail lights of vehicles can be used to do effective communication with each other which would lead to effective traffic safety and management.

\section{5) Underwater navigation and communication}

Li-Fi technology can be used in underwater navigation and communication purposes as light can easily passes through water.

\section{6) Smart lighting:}

Li-Fi hotspots can be created using street lamps, digital advertising boards.

\section{7) Internet of things}

Devices such as smart phones, tablets, laptops, smart watches, etc can be interconnected with each other using Li-Fi technology for high speed and improved safety and security. 


\section{Conclusion}

As Li-Fi technology is still in its early stages, there is tremendous scope for its innovation and applications. Nowadays, many devices such as smartphones ,laptop, tablets, smart watches etc access wireless internet so limited frequency spectrum of radio waves used in $\mathrm{Wi}-\mathrm{Fi}$ is facing many issues making $\mathrm{Li}-\mathrm{Fi}$ more reliable and high speed system. By replacing other lights with LED lights we will proceed towards greener, cleaner, brighter and safe future.

\section{References:}

1) Haas, Harald (July 2011). "Wireless data from every light bulb". TED Global. Edinburgh, Scotland

2) International Journal of Trend in Scientific Research and Development (IJTSRD) Volume: 3 | Issue: 3 | Mar-Apr 2019

3) D. T sonev, S. Sinanovice, and H. Haas, "Enhanced Subcarrier Index Modulation (SIM) OFDM" in Proc. Of IEEE Global Communications Conference (IEEE GLOBECOM 2011), Houston, Texas, USA, 5-9 Dec. 2011.

4) International Journal of Applied Engineering Research, ISSN 0973-4562 Vol.7 No.11 Research India Publications, 2012

5) LI-FI TECHNOLOGY BASED AUDIO AND TEXT TRANSMISSION 2019 4th International Conference on Recent Trends on Electronics, Information, Communication \& Technology (RTEICT-2019), MAY 17th \& 18th 2019

6) National Conference on "Advanced Technologies in Computing and Networking"-ATCON-2015 Special Issue of International Journal of Electronics, Communication \& Soft Computing Science and Engineering

7) Li-Fi Technology: Increasing the Range of Li-Fi by Using Mirror Published Online January 2019 in MECS

8) Image and Data Transmission using Visible Light Communication (Li-Fi) International Journal of Research in Engineering, Science and Management Volume-2, Issue-3, March-2019 